\title{
Erratum to: Sexual dimorphism of the tibia in contemporary Greeks, Italians, and Spanish: forensic implications
}

\author{
Elena F. Kranioti ${ }^{1,2} \cdot$ Mario A. Apostol ${ }^{3}$
}

Published online: 3 November 2016

(C) Springer-Verlag Berlin Heidelberg 2016

\section{Erratum to: Int J Legal Med (2015) 129:357-363 \\ DOI 10.1007/s00414-014-1045-6}

The manuscript Int J Legal Med 129:357-363 contains a numerical error in Table 4. More specifically in the coefficient for UB (upper epiphyseal breadth) which in the equation IF4 for the Italians is 0.1739 instead of 0.1379 as appears in the original publication. The corrected version of Table 4 of the original publication can be seen in Table 4 (corrected).
Consequently, the formula for sex estimation in Italians using two variables $(\mathrm{UB}=$ upper epiphyseal breadth and $\mathrm{LB}=$ lower epiphyseal breadth) is the following:

$\mathrm{IF} 4=0.1739 * \mathrm{UB}+0.1460 * \mathrm{LB}-19.1636$

An example of the application of the formula is given below:

The online version of the original article can be found at http:// dx.doi:10.1007/s00414-014-1045-6.

Elena F. Kranioti

elena.kranioti@ed.ac.uk

1 Edinburgh Unit for Forensic Anthropology, School of History, Classics and Archaeology, University of Edinburgh, Edinburgh EH8 9AG, Scotland, UK

2 Department of Forensic Sciences, University of Crete Medical School, 71110 Heraklion, Crete, Greece

3 SC Medicina Legale-ASL TO4, Ivrea, TO, Italy 
Table 4 All subset discriminant functions and classification accuracies for the three populations and the pooled sample

\begin{tabular}{|c|c|c|c|c|c|c|c|c|c|c|c|c|c|c|c|}
\hline & & \multicolumn{3}{|c|}{ Coefficients } & \multirow[t]{2}{*}{ Constant } & \multicolumn{2}{|l|}{ Male } & \multicolumn{2}{|l|}{ Female } & \multirow{2}{*}{$\begin{array}{l}\text { Total } \\
\%\end{array}$} & \multicolumn{2}{|l|}{ Male } & \multicolumn{2}{|l|}{ Female } & \multirow{2}{*}{$\begin{array}{l}\text { Tota } \\
\%\end{array}$} \\
\hline & & $\mathrm{TL}$ & UB & LB & & $N$ & $\%$ & $N$ & $\%$ & & $N$ & $\%$ & $N$ & $\%$ & \\
\hline \multirow[t]{4}{*}{ Greek sample } & GF1 & 0.0244 & 0.1116 & 0.1204 & -21.6294 & $75 / 85$ & 88.2 & $59 / 71$ & 83.1 & 85.9 & $75 / 85$ & 88.2 & $59 / 71$ & 83.1 & 85.9 \\
\hline & GF2 & 0.0297 & 0.1576 & & -21.6321 & $76 / 85$ & 89.4 & $60 / 72$ & 83.3 & 86.6 & $75 / 85$ & 88.2 & $59 / 72$ & 83.1 & 85.4 \\
\hline & GF3 & 0.0344 & & 0.1993 & -20.4757 & $76 / 85$ & 89.4 & $62 / 71$ & 87.3 & 88.5 & $75 / 85$ & 88.2 & $62 / 71$ & 87.3 & 87.8 \\
\hline & GF4 & & 0.1724 & 0.1527 & -18.9237 & $76 / 85$ & 89.4 & $61 / 71$ & 85.9 & 87.8 & $76 / 85$ & 89.4 & $61 / 71$ & 85.9 & 87.8 \\
\hline \multirow[t]{4}{*}{ Spanish sample } & $\mathrm{SF} 1$ & 0.0096 & 0.2669 & 0.0002 & -22.5316 & $40 / 42$ & 95.2 & $46 / 50$ & 92.0 & 93.5 & $40 / 42$ & 95.2 & $46 / 50$ & 92.0 & 93.5 \\
\hline & SF2 & 0.0072 & 0.2793 & & -22.6016 & $41 / 43$ & 95.3 & $49 / 53$ & 92.5 & 93.8 & $41 / 43$ & 95.3 & $49 / 53$ & 92.5 & 93.8 \\
\hline & SF3 & 0.034 & & 0.1595 & -19.6229 & $39 / 46$ & 84.8 & $47 / 54$ & 87.0 & 86.0 & $38 / 46$ & 82.6 & $47 / 54$ & 87.0 & 85.0 \\
\hline & SF4 & & 0.2980 & 0.0066 & -21.8219 & $40 / 42$ & 95.2 & $46 / 50$ & 92.0 & 93.5 & $40 / 42$ & 95.2 & $45 / 50$ & 90.0 & 92.4 \\
\hline \multirow[t]{4}{*}{ Italian sample } & IF1 & 0.0132 & 0.1478 & 0.1204 & -20.7166 & $68 / 81$ & 84.0 & $96 / 105$ & 91.4 & 88.2 & $67 / 81$ & 82.7 & $96 / 105$ & 91.4 & 87.6 \\
\hline & IF2 & 0.018 & 0.1854 & & -19.8181 & $69 / 81$ & 85.2 & $95 / 106$ & 89.6 & 87.7 & $69 / 81$ & 85.2 & $94 / 106$ & 88.7 & 87.2 \\
\hline & IF3 & 0.0225 & & 0.2290 & -18.0086 & $67 / 81$ & 82.7 & $93 / 107$ & 86.9 & 85.1 & $67 / 81$ & 82.7 & $93 / 107$ & 86.9 & 85.1 \\
\hline & IF4 & & 0.1739 & 0.1460 & -19.1636 & $68 / 81$ & 84.0 & $96 / 105$ & 91.4 & 88.2 & $68 / 81$ & 84.0 & $96 / 105$ & 91.4 & 88.2 \\
\hline \multirow[t]{4}{*}{ Pooled sample } & $\mathrm{F} 1$ & 0.0183 & 0.1690 & 0.0505 & -20.8371 & $181 / 208$ & 87.0 & $200 / 226$ & 88.5 & 87.8 & $180 / 208$ & 86.5 & $200 / 226$ & 88.5 & 87.6 \\
\hline & F2 & 0.0196 & 0.1890 & & -20.458 & $183 / 209$ & 87.6 & $198 / 231$ & 85.7 & 86.6 & $183 / 209$ & 87.6 & $198 / 231$ & 85.7 & 86.6 \\
\hline & F3 & 0.0372 & & 0.1213 & -18.3472 & $167 / 212$ & 78.8 & $201 / 232$ & 86.6 & 82.8 & $167 / 212$ & 78.8 & $200 / 232$ & 86.2 & 82.7 \\
\hline & F4 & & 0.2255 & 0.0543 & -18.7601 & $175 / 208$ & 84.1 & $198 / 226$ & 87.6 & 85.9 & $175 / 208$ & 84.1 & $198 / 226$ & 87.6 & 85.9 \\
\hline
\end{tabular}

For a tibia, deriving from an individual of Italian origin, if $\mathrm{LB}=39 \mathrm{~mm}$ and $\mathrm{UB}=65 \mathrm{~mm}$ by replacing the unknown in (1) we get:

$\mathrm{IF} 4=0.1739 * 65+0.1460 * 39-19.1636=-2.167$

Thus, IF $4<0$ means that the unknown tibia belongs to a female individual. This value is smaller than -1.18 which according to Table 5 of the original publication (Int J Legal Med 129 (2015):357-363) means that the posterior probability of correct classification of this individual is $>95 \%$.
Acknowledgments We would like to acknowledge the discovery of this numerical error by an anonymous reviewer of Kotěrová et al. IJLM 2016 (in press). As seen above, the numerical error is due to reverse order of two digits which unfortunately resulted in erroneous results in the aforementioned validation study. We would like to suggest that researchers should get in touch with the authors of the original publications and request access to the original data in such cases as we feel that the exclusion of IF4 from this important validation study could have been omitted. Nevertheless, we are grateful to have the opportunity to provide a correction for our formula. 